Proceedings of SALT 26: 205-223, 2016

\title{
Scalar implicatures in non-monotonic environments *
}

\author{
Takashi Morita \\ Massachusetts Institute of Technology
}

\begin{abstract}
Scalar implicatures (SIs) have been traditionally analyzed as pragmatic inferences that arise after semantic computation. Recent studies, however, have presented various challenges to this classic analysis; for instance, it has been claimed that SIs can be interpreted within the scope of various semantic operators. These observations motivate a grammatical analysis of SIs: SIs are derived during or before semantic computation. Among various kinds of evidence for the grammatical approach to SIs, an especially convincing one is SIs embedded in non-monotonic (NM) environments, which post-semantic analyses have difficulty deriving. This paper introduces a new example of NM operators that allow the SI-embedding in their scope, and I thereby provide further empirical support for the grammatical analysis. On the other hand, I will also show that not all NM operators behave in the same way with respect to SI-embedding. It will turn out that Strawson nonmonotonicity is required to embed SIs in the negative component of NM environments; i.e. SI-embedding is unavailable if the NMity can be decomposed into monotonic assertion and monotonic presupposition.
\end{abstract}

Keywords: scalar implicature, non-monotonic environment, Japanese

\section{Introduction}

Traditionally, scalar implicatures (SIs) have been analyzed as pragmatic inferences that arise after semantic computation. Recent studies, however, have presented various challenges to this classic view; for instance, it has been claimed that SIs can be interpreted within the scope of various semantic operators (Chierchia 2004, 2006; Chierchia, Fox \& Spector 2011). These observations motivate a grammatical analysis of SIs: SIs are derived during or before semantic computation.

Among various kinds of evidence for the grammatical analysis, an especially convincing one is SIs embedded in non-monotonic (NM) environments, which postsemantic analyses have difficulty deriving (Chierchia 2004; Chierchia et al. 2011). This paper introduces new examples of NM operators that allow SIs to be embed-

* I am grateful to Irene Heim, Danny Fox, and the anonymous reviewers and the participants in SALT 26. All errors are, of course, my own. This work is partially funded by the Kikawada Foundation.

(C)2016 Morita 
ded in their scope, and thereby provides further empirical support for the grammatical analysis. On the other hand, I will also show that not all NM operators behave in the same way with respect to SI-embedding. It will turn out that Strawson non-monotonicity is required to embed SIs in the negative component of NM environments; i.e. SI-embedding is unavailable if the NMity can be decomposed into monotonic assertion and monotonic presupposition.

The rest of the present paper is organized as follows. §2 introduces a new example of NM operators that allow SI-embedding in their scope, and then explains why it is challenging to post-semantic analyses while the grammatical analysis provides straightforward derivation for it. $\$ 3$ observes that not all NM environments allow embedded SIs. I will propose that the necessary and sufficient condition for SI-embedding in the negative component of NM environments is their Strawson non-monotonicity, and this generalization is correctly predicted by the analysis by Sharvit \& Gajewski (2008) and Gajewski \& Sharvit (2012). §4 provides evidence for Strawson non-monotonicity of NM operators that allow embedded SIs, and thereby justifies my assumptions made in the proposal in $\S 3$. $\$ 5$ concludes.

\section{SIs embedded in NM environments}

One of the most convincing arguments for the grammatical analysis of SIs is that SIs can be embedded in (some) NM environments (Chierchia 2004; Chierchia et al. 2011). This section first shows that a restrictive particle in Japanese, dake, provides an example of such environments. I will then perform a grammatical analysis of the embedded SIs, and explain why they are challenging to Gricean and other postsemantic analyses.

\subsection{Dake and embedded SIs}

Dake is a restrictive particle in Japanese. Dake poses a two-fold truth condition: prejacent and exhaustification. For (1) to be true, for instance, both (1a) and (1b) must be satisfied. (The focus of restrictive particles is on the CAPITALIZED phrase in this paper.)

(1) TARO-dake ki-ta.

Taro-only come-PST

'Only Taro came.'

a. Prejacent: Taro came.

b. Exhaustification: People other than Taro did not come.

Note that neither the prejacent nor the exhaustification of dake is cancellable. 
Scalar implicatures in non-monotonic environments

A remarkable property of dake is that we can embed SIs in its scope. (Later, I will show that this is not possible for only in English.) Consider (2).

MARY-dake ringo-ka banana-o tabe-ru.

Mary-only apple-or banana-ACC eat-PRES

'Only Mary eats an apple or a banana.'

a. Prejacent: Mary eats an apple or a banana.

b. Exhaustification: It is not the case that the others eat an apple or a banana and not both. (They may eat both.)

In (2), a disjunction $k a$ appears in the scope of dake. This disjunction can be exclusively interpreted. The natural interpretation of the prejacent (2a) is that Mary eats the apple or the banana but not both. Moreover, the exhaustification (2b), which negates the disjunctive proposition the others eat an apple or a banana, leaves it possible that they eat both the apple and the banana. We can confirm this interpretation of exhaustification by (4), where it is explicitly asserted that the other people eat both, assuming the context in (3).

(3) Context: Every morning, a dining hall provides an apple and a banana to each student. Mary does not eat much for breakfast, so she eats only one of the fruits. (Which one she eats varies day by day.) The other students eat both.

(4) MARY-dake ringo ka banana-o tabe(-te), hoka-no hito-wa

Mary-only apple or banana-ACC eat-CONJ other-NOM person-TOP (minna) ryoohoo tabe-ru.

all both eat-PRES

'Only Mary eats the apple or the banana and not both, and the others eat both.'

If the negated disjunction were inclusive, the second half of the sentence would cause a contradiction with the first. The felicity of (4) indicates that the disjunction is exclusively interpreted in the exhaustification. Note that stress on the disjunction, which enables exclusive readings even in DE environments (Cohen 1971; Horn 1985; Chierchia et al. 2011; Spector 2013; Fox \& Spector To appear), is unnecessary here. Parallel results are obtained with other scalar items: an existential quantifier (5) and numerals ${ }^{1}(6)$.

1 The possibility of exactly-reading of numerals in the scope of dake may be less surprising because such reading is possible even in DE environments (Spector 2013). 


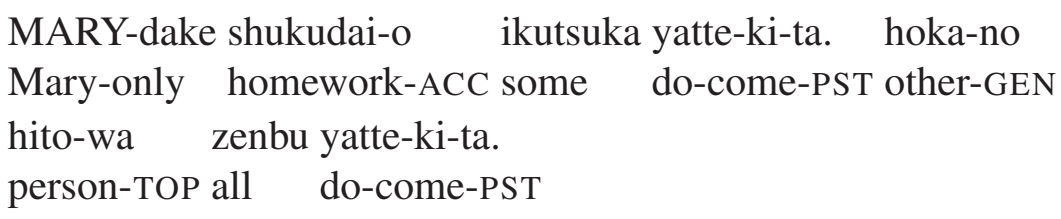

'Only Mary did some homework. The others did all.'

(6) MARY-dake ringo-o san-ko kat-ta. hoka-no hito-wa go-ko Mary-only apple-ACC three-CL buy-PST other-GEN person-TOP five-CL kat-ta. buy-PST

'Only Mary bought three apples. The others bought five.'

Just as in (4), the people other than Mary can take stronger alternative options (all and five) than she does (some and three) in (5) and (6). All these examples are analyzable with embedded SIs: the stronger alternatives are double-negated first by SIs and later by dake, and thus, they are ultimately positive in the exhaustification. The next subsection explains this idea in detail.

\subsection{Grammatical analysis}

Let us illustrate a grammatical analysis of the embedded SI in (2). The basic idea of the grammatical analysis is that SIs are introduced in a linguistic module (or semantics), not after semantic computations. There are two major streams in this approach. One assumes that scalar items have a pair of literal and exhausted semantic values in their lexical entry, and compositional semantics computes both the literal and exhausted values in parallel. Finally, the stronger value in the output pair of the computation is chosen as the sentential meaning (Chierchia 2004; Sharvit \& Gajewski 2008; Gajewski \& Sharvit 2012). The other branch assumes a phonologically null semantic operator that conjoins a SI to the prejacent (Chierchia 2006; Fox 2007; Chierchia et al. 2011). In the next section, we will see that the parallel computation of the literal and exhausted meanings proposed in (Chierchia 2004; Sharvit \& Gajewski 2008; Gajewski \& Sharvit 2012) is essential to explain the distribution of SIs, and the standard operator analysis, in which the literal meaning is lost once the operator applies, fails. In order to emphasize the common advantage of grammatical analyses, however, I refrain from choosing any specific implementation for now. Instead, I simply demonstrate how embedding an SI derives the truth condition in (2).

Let $m$ be [[Mary]], and for an arbitrary individual $c$, let $A(c)$ and $B(c)$ denote ' $c$ eats the apple' and ' $c$ eats the banana' respectively for shorthand. The truth 
Scalar implicatures in non-monotonic environments

condition in (2) is derived as follows.

$$
\begin{array}{rlr} 
& A(m) \vee B(m) & \\
\stackrel{\text { SI }}{\mapsto}(A(m) \vee B(m)) \wedge \neg(A(m) \wedge B(m)) & \\
\stackrel{\text { dake }}{\mapsto}(A(m) \vee B(m)) \wedge \neg(A(m) \wedge B(m)) & \text { Prejacent } \\
& \wedge \forall x[x \neq m \rightarrow \neg((A(x) \vee B(x)) \wedge \neg(A(x) \wedge B(x)))] & \text { Exh. } \\
\Longleftrightarrow & (A(m) \vee B(m)) \wedge \neg(A(m) \wedge B(m)) & \text { Prejacent } \\
& \wedge \forall x[x \neq m \rightarrow(\neg A(x) \wedge \neg B(x)) \vee \underline{(A(x) \wedge B(x))]} & \text { Exh. } \\
\Longleftrightarrow & {[(2)]}
\end{array}
$$

The input of derivation is the inclusive disjunction (7). First, the SI negates the conjunctive expression $(A(m) \wedge B(m))$ This results in the exclusive disjunction $((A(m) \vee$ $B(m)) \wedge \neg(A(m) \wedge B(m)))$. Then, dake takes this exclusive disjunction as its input. The exhaustification of dake negates every proposition that is just like the prejacent but an alternative individual $x$ replaces $m(9)$. As a result, the previously negated conjunction (underlined in (9)) gets another negation, which is equivalent to no negation (underlined in (10)). Accordingly, eating both the apple and the banana becomes a possible option to the alternatives to Mary.

\subsection{Partial weakening problem of post-semantic analyses}

The grammatical approach provides a straightforward analysis of (2), embedding an SI in the scope of dake. On the other hand, such an analysis is not available to post-semantic approaches to SIs such as Gricean theory (Grice 1975); in these frameworks, SIs cannot be obtained before dake is computed.

Moreover, it would be difficult to derive the truth condition in (2) without embedding the SI. This is because the negation of inclusive disjunction (the nonexhausted proposition) is stronger than that of exclusive disjunction (the exhausted proposition). Consider what happens if no SI is embedded in the scope of dake.

$$
\begin{aligned}
& A(m) \vee B(m) \\
& \stackrel{\text { dake }}{\mapsto}(A(m) \vee B(m)) \\
& \wedge \forall x[x \neq m \rightarrow \neg(A(x) \vee B(x))]
\end{aligned}
$$

The exhaustification of dake in (13) is stronger than that in (10), repeated in (14).

$$
\begin{array}{lr}
(A(m) \vee B(m)) \wedge \neg(A(m) \wedge B(m)) & \text { Prejacent } \\
\wedge \forall x[x \neq m \rightarrow(\neg A(x) \wedge \neg B(x)) \vee \underbrace{(A(x) \wedge B(x))}_{\text {Weakening }}] & \text { Exh. }
\end{array}
$$


The negation of the exclusive disjunction in (14) provides people other than Mary with an additional option: they can eat both the apple and the banana. This is unavailable with the negation of the inclusive disjunction in (13). Therefore, deriving the truth condition of (2) without embedding the SI would require a mechanism to partially ${ }^{2}$ weaken a given semantic value. This has been claimed to be impossible in the Gricean account (Russell 2006); a cooperative speaker can only strengthen semantic values. Every post-semantic analysis of SIs would face this problem of partial weakening because they cannot derive the SI before computing dake. Hence, (2) (together with (5) and (6)) empirically supports the grammatical analysis of SIs.

\section{Blocking of SIs}

In the previous section, we saw that SIs can be embedded in the scope of dake. However, not all NM operators allow this embedding. For example, we will soon see that the embedding is impossible for only in English. This section subclassifies $\mathrm{NM}$ environments and discusses the licensing condition for SIs.

\subsection{NM operators with presupposition}

\subsubsection{Only}

Unlike dake, only in English does not allow the SI-embedding in its exhaustification. Consider (15) under the context in (3).

$$
\text { \# Only Mary eats the apple or the banana. The others eat both. }
$$

Recall that if the negated disjunction in the exhaustification were exclusive, it would be possible that people other than Mary eat both the apple and the banana. (15) forces this reading by its second sentence and it exhibits a contradiction unless we place stress on or. Note that the sentence becomes felicitous if the other people take a third option and eat neither the apple or the banana. Consider (17) under the context in (16).

(16) Context: Every morning, a dining hall provides an apple, a banana, and an orange to each student. Mary does not like oranges, so she eats either the apple or the banana. (Which one she eats varies day by day.) The other students, in contrast, do not like apples or bananas, so they choose oranges.

Only Mary eats the apple or the banana. The others eat an orange.

2 Note that neither (13) nor (14) is stronger than the other as a whole proposition. This is because the prejacent is stronger in (14) than in (13). 
Scalar implicatures in non-monotonic environments

The infelicity of (15), together with the felicity of (17), indicates that the negated disjunction is inclusive, not exclusive. Note, however, that people seem to still have the exclusive interpretation of the disjunction in the prejacent of only: Mary eats the apple or the banana and not both. We will discuss this point in detail in the next subsection.

\subsubsection{Shika}

Another Japanese restrictive particle, shika, behaves in the same way as only. In simple sentences like (18), shika poses the same two-fold truth condition as dake.

(18) TARO-shika ko-nakat-ta.

Taro-only come-NEG-PAST

'Only Taro came.'

a. Prejacent: Taro came.

b. Exhaustification: People other than Taro did not come.

Note that shika is an $\mathrm{N}$-word and must co-occur with a negation. The focus particle and negation together mean 'only'.

When shika takes a disjunction in its scope, we see that its exhaustification does not allow the exclusive disjunction. Consider (19a) and (19b) ${ }^{3}$.

a. \# MARY-shika ringo-ka banana-o tabe-zu, hoka-no hito-wa Mary-only apple-or banana-ACC eat-NEG other-NOM person-TOP (minna) ryoohoo tabe-ru. all both eat-PRES

'Only Mary eats the apple or the banana, and the others eat both.'

b. MARY-shika ringo-ka banana-o tabe-zu, hoka-no hito-wa Mary-only apple-or banana-ACC eat-NEG other-NOM person-TOP (minna) mikan-o tabe-ru. all orange-ACC eat-PRES

'Only Mary eats the apple or the banana, and the others eat an orange.' (19a) and (19b) have a disjunction $k a$ within the scope of shika. (19a) is contradictory, with its second half expressing that the other people eat both the apple and

3 If one finds the context (16) not helpful enough to felicitate (19b), suppose in addition that the dining hall is recommending students to eat the apples or bananas, not the oranges (for example because oranges are getting expensive these days). Despite of this recommendation, students other than Mary eat the oranges. Native speakers of Japanese seem to prefer this more detailed context for the sentence. 
the banana ${ }^{4}$. On the other hand, no contradiction occurs if the other people take a third choice, neither the apple or the banana (19b). These observations suggest that shika, unlike dake, does not allow an SI in its exhaustification. Note that here again, the prejacent conveys an inference that Mary eats the apple or the banana and not both. Thus, just as in the case of only, the SI seems to survive in the prejacent of shika, but not in the exhaustification.

\subsubsection{Almost}

After observing that only and shika do not allow SIs, one may think it is because they behave just like downward entailing (DE) operators, which prohibit SIs environments (Horn 1972; Fauconnier 1975; Gazdar 1979; Atlas \& Levinson 1981; Horn 1989; Levinson 2000; Chierchia 2004; Russell 2006; Spector 2013). For example, Chierchia $(2004,2006)$ argues that SIs are blocked wherever negative polarity items (NPIs) are licensed. More formally speaking, one may hypothesize that SIs are prohibited in Strawson downward entailing environments (Sharvit \& Gajewski 2008; Gajewski \& Sharvit 2012).

(20) Strawson downward entailingness (SDEness) (von Fintel 1999)

A function $f$ of type $\langle\sigma, \tau\rangle$ is Strawson downward entailing (SDE).

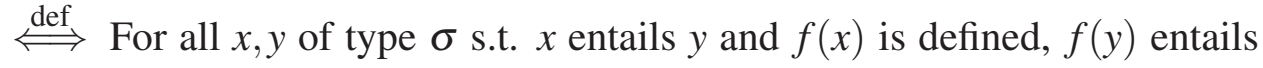
$f(x)$.

In other words, a semantic function is SDE iff it is DE given that its presuppositions are all satisfied. For example, only is SDE because it presupposes the prejacent and asserts the exhaustification (Horn 1969; von Fintel 1999) and the exhaustification is DE. Because DE operators are also SDE, one may propose that SIs are not licensed in SDE environments. This would prevent SIs from appearing in the scope of only.

The next subsection will show that distinguishing presuppositions from assertions is in fact a key to generalization of SIs' distribution. However, SDEness is not a necessary anti-licensing condition of SIs. This is because SIs are blocked even in presuppositions. Consider almost for example. This adverb also conveys a two-fold semantic value.

(21) Gore almost won. (Horn 2002)

a. Gore "came close to" winning.

4 One difference between (15) and (19a) is that stress on the disjunction seems not to help the interpretation of the latter while the former becomes felicitous with this stress (Cohen 1971; Horn 1985; Chierchia et al. 2011; Spector 2013; Fox \& Spector To appear). This contrast is out of the scope of the current paper, but it will be crucial data for future studies on SI-licensing by stress. 
Scalar implicatures in non-monotonic environments

b. Gore did not win.

The semantic value above indicates almost is NM as a whole (Atlas 1997; Horn 2002): (21a) is upward entailing (UE) (e.g. Gore "came close to" winning a baseball game. entails Gore "came close to" win a game.) while (21b) is DE. An important preliminary observation is that the assertion of almost is the UE component, and the DE component is secondary (Ducrot 1973; Horn 1996, 2002). Some symptoms of this are that almost does not license NPIs (Horn 1996, 2002), nor does it trigger negative inversion (Horn 2002). While people have given various names to this negative inference by almost (see Horn (2002)), let me assume it to be a presupposition following Ducrot (1973) and Horn (1996). In the next section, I will introduce an enhanced version of presupposition test, and Appendix applies this test to almost to justify this assumption.

Given that the negative inference of almost is presupposed, the adverb is not SDE, but Strawson upward entailing (SUE). Therefore, nothing would prevent SIs from any inference of almost if the anti-licensing condition of SIs is just SDE environments. On the contrary, the fact is that SIs are blocked from the negative inference of almost. Consider (23) under the context (22).

(22) Context: John is a faculty member of the department of linguistics in some university. John usually teaches either "Syntax" or "Semantics" in fall. (He does not want to teach both because he wants to have time for his research.) Another faculty member, Mary, teaches the other course. As usual, it was planned that John and Mary would teach the two courses this fall. However, Mary got in a traffic accident and was seriously injured. She was no longer able to teach any class. Accordingly, John had to teach both. Suppose that someone just asked you whether John taught either "Syntax" or "Semantics" (and not both) as usual.

(23) \# John almost taught "Syntax" or "Semantics". But he had to teach both.

(23) is infelicitous unless or bears stress. If an SI survives in the negative presupposition of almost, the resulting inference would be the negation of the exclusive disjunction: John taught neither "Syntax" nor "Semantics", or he taught both of them. The infelicity of (23) indicates that the disjunction is interpreted inclusively. Note that the sentence becomes felicitous if we explicitly express the exclusiveness as in (24).

(24) John almost taught "Syntax" or "Semantics" and not both. But he had to teach both.

Also, there is no contradiction when John taught neither "Syntax" nor "Semantics". Suppose that Mary was also responsible for "Introduction to Linguistics", and John 
had to teach this course instead of her (and someone else taught "Syntax" and "Semantics").

(25) John almost taught "Syntax" or "Semantics". But he had to teach "Introduction to Linguistics".

The blocking of an SI in the negative presupposition of almost suggests that SDEness is not necessary to describe the anti-SI condition.

\subsection{Generate locally, evaluate globally}

While SDEness is not the exact anti-licensing condition for SIs, decomposing NM environments into assertions and presuppositions is the key to understanding the blocking of SIs.

Recall that a disjunction is interpreted exclusively in the prejacent of only but inclusively in the exhaustification (15). Therefore, whether an SI applies or not is independently determined in assertions and presuppositions. This observation has already been made by Sharvit \& Gajewski (2008) (and later in Gajewski \& Sharvit (2012)) with a factive predicate sorry.

(26) John is sorry that the boss or her assistant disappeared. (Sharvit \& Gajewski 2008; Gajewski \& Sharvit 2012)

(26) presupposes that the boss or her assistant disappeared, and usually this disjunction is exclusively interpreted. On the other hand, the disjunction is interpreted inclusively in the assertion. In particular, (26) does not mean (27).

(27) John is sorry that the boss or her assistant, but not both, disappeared. (Sharvit \& Gajewski 2008; Gajewski \& Sharvit 2012)

This is exactly the same pattern as only in (15), and thus, we can directly apply Sharvit \& Gajewski's analysis to the SDE operators above.

Sharvit \& Gajewski's analysis, based on Chierchia (2004), is summarized as follows.

(28) SI generation/evaluation procedure (Sharvit \& Gajewski 2008; Gajewski \& Sharvit 2012)

a. Scalar items are lexically associated with a pair of semantic values: literal/logical value and exhausted value.

b. These two values are computed in parallel throughout compositional semantics. 
Scalar implicatures in non-monotonic environments

c. When a presupposition appears, it obtains a copy of the paired meanings independent of the ones in the assertion thread.

d. Once the compositional computation is done, choose the stronger member of the pair unless it causes contradiction with discourse. If there is a presupposition as well as an assertion, independently choose the stronger meaning for each.

There are two essential components in this analysis. First, both the literal and exhausted semantic values are kept throughout computation. This is contrasted by the standard operator analysis (Chierchia 2006; Fox 2007; Chierchia et al. 2011), in which the literal meaning goes out of access once the exhausted meaning is introduced. Keeping both the meanings available enables us to select the stronger one at the final stage of computation. This choice of the stronger semantic value prevents SIs in DE environments, where the exhausted meaning becomes weaker and it is simply not selected. At the same time, it is possible to embed SIs in various semantic operators because the exhausted meaning is present from the beginning of computation (in the lexicon). In short, SIs are generated locally, but whether they apply or not is evaluated globally in comparison with the literal meaning. Note that cancellation of SIs is treated as avoidance of contradiction with discourse in (28d).

The second essential point of Sharvit \& Gajewski's analysis is that the literal and exhausted meanings compete in two independent matches: assertions and presuppositions. This makes it possible to apply an SI in a presupposition and block it in an assertion (and vice versa). For example, we saw that an SI appears in the prejacent (presupposition) of only but not in the exhaustification (assertion) (15). Sharvit \& Gajewski's procedure derives this pattern as follows. First, before the application of only, there is a pair of semantic values associated with the scalar item, or.

$$
\begin{aligned}
& {[\text { Mary eats the apple or the banana }] } \\
= & \langle\underbrace{A(m) \vee B(m)}_{\text {Literal }}, \underbrace{(A(m) \vee B(m)) \wedge \neg(A(m) \wedge B(m))}_{\text {Exhaustive }}\rangle
\end{aligned}
$$

The first member of the pair is the literal meaning without SI, and the second is the exhausted meaning with SI. When only applies to this, each of its assertion and presupposition gets a pair of semantic values (30)-(31). And these pairs are evaluated so that their stronger members are chosen as the final values of the assertion and presupposition independently. In the presupposition, the exhausted meaning is stronger than the literal one (exclusive vs. inclusive disjunction), so the exhausted value is selected (32). In the assertion, on the other hand, the literal meaning is 
stronger and selected (33).

$$
\begin{aligned}
\text { (29) } \stackrel{\text { only }}{\mapsto} \text { Presup.: } & \overbrace{\langle A(m) \vee B(m)}^{\text {Literal }}, \overbrace{(A(m) \vee B(m)) \wedge \neg(A(m) \wedge B(m))} \\
\text { Assert: } & \overbrace{\langle\forall x[x \neq m \rightarrow \neg A(x) \wedge \neg B(x)]}^{\text {Literal }}, \\
\underbrace{\forall x[x \neq m \rightarrow(\neg A(x) \wedge \neg B(x)) \vee(A(m) \wedge B(m))]}_{\text {Literal }}\rangle & \text { Exhaustive }
\end{aligned}
$$

Although Sharvit \& Gajewski only discuss SDE environments, their analysis makes a parallel prediction about SUE environments. The exhausted meaning is stronger and thus is selected in their DE presupposition whereas the literal meaning is stronger and selected in their UE assertion. This explains the interpretation of disjunction in the scope of almost (23).

\subsection{Analysis of SNM operators}

We saw that Sharvit \& Gajewski's procedure correctly derives independent application/blocking of SIs in assertions and presuppositions. How does it derive the truth condition for the example with dake (2)? Unlike the case of only, the negative inference does involve an SI there In order to deal with the case, we need a small modification to the final evaluation process. Sharvit \& Gajewski's procedure selects the stronger member of a semantic value pair. However, it is possible that neither member of the pair is stronger than the other, and in this case, the procedure would crash. This happens with Strawson non-monotonic (SNM) operators, and I propose that dake is SNM. I will motivate this proposal in the next section. In order to avoid the computational crash, we would need to set a default value for the evaluation.

Evaluation procedure (revised from (28d))

a. If either the literal or exhausted meaning is stronger than the other, then choose the stronger meaning.

b. Otherwise (i.e. if neither is stronger), choose the exhausted meaning.

The default semantic value is assumed to be the exhausted meaning. This setting of a default value has been adopted implicitly in literature (Chierchia 2004: "Strength Condition", Fox \& Spector To appear: "economy condition"). 
Scalar implicatures in non-monotonic environments

Given this revision, the SI embedded in the scope of dake (2) is computed as follows. The first step (29) is the same. The difference between dake and only is that dake asserts both the prejacent and the exhaustification. Therefore, it is impossible to independently strengthen both of them.

$$
\begin{aligned}
& \text { Literal } \\
& \text { (29) } \stackrel{\text { dake }}{\mapsto} \overbrace{A(m) \vee B(m) \wedge \forall x[x \neq m \rightarrow \neg A(x) \wedge \neg B(x)]} \text {, } \\
& (A(m) \vee B(m)) \wedge \neg(A(m) \wedge B(m)) \\
& \underbrace{\wedge \forall x[x \neq m \rightarrow(\neg A(x) \wedge \neg B(x)) \vee(A(m) \wedge B(m))]}\rangle \\
& \text { Exhaustive } \\
& \underset{(34 \mathrm{~b})}{\stackrel{\text { Eval. }}{\longmapsto}}(A(m) \vee B(m)) \wedge \neg(A(m) \wedge B(m)) \\
& \underbrace{\wedge \forall x[x \neq m \rightarrow(\neg A(x) \wedge \neg B(x)) \vee(A(m) \wedge B(m))]}_{\text {Exhaustive }}
\end{aligned}
$$

Neither the literal or exhausted meaning is stronger than the other in (35). Therefore, the exhausted meaning is selected by default (36), which yields the SI in the exhaustification of dake.

\section{Evidence for SNMity}

The analysis in (35)-(36) is based on the assumption of SNMity of dake; dake asserts both the prejacent and exhaustification, and thus, it is impossible to strengthen them independently as an assertion and a presupposition. However, this assumption is not supported by the previous literature, which has claimed that dake's primary meaning is the prejacent and the exhaustification is secondary (Kuno 1999; Numata 2000; Mogi 2001). If this means that the exhaustification is presuppositional, then dake would be SUE just as almost, and the above analysis predicts no SI in its exhaustification. This section justify my assumptions about SNMity with an enhanced version of presupposition test to NM operators.

\subsection{Enhancing presupposition tests}

Results of standard presupposition tests to dake (and shika) are reported by Yoshimura (2007: 324-325). On the contrary to the claim by many researchers that the primary meaning of dake is the prejacent, she reports that the prejacent is presupposed and the exhaustification is at issue according to the negation and question tests. 
a. AKIRA-dake kaigi-ni ki-ta wakedewanai. Akira-only meeting-DAT come-PST it.it.not.the.case (Yoshimura 2007)

b. AKIRA-shika kaigi-ni ko-nakat-ta wakedewanai. Akira-only meeting-DAT come-DAT it.is.not.the.case

'It is not the case that only Akira came to the meeting.'
a. AKIRA-dake kaigi-ni ki-ta-no? (Yoshimura 2007) Akira-only meeting-DAT come-PST-Q
b. AKIRA-shika kaigi-ni ko-nakat-ta-no? Akira-only meeting-DAT eat-NEG-PST-Q
'Did only Akira come to the meeting?'

According to Yoshimura, the prejacent is preserved under negation in (37) and question in (38) while the exhaustification is negated in (37) and in question in (38), whether the restrictive particle is dake (a) or shika (b). .

However, the tests above fail to take into account influence of context. To see what I mean, suppose that dake asserts the conjunction of its prejacent and exhaustification as I proposed. Then, in order for (37a) to be true, (39a) or (39b) has to be false.
a. Akira came.
b. The other people did not come.

Importantly, there is no need for both to be false. Accordingly, it is possible that people's prior experiences bias them to assign 1 to the prejacent (39a) and 0 to the exhaustification (39b) for this particular example. If dake in fact presupposes its prejacent, on the other hand, the negation test forces people to assign 1 to the prejacent and 0 to the exhaustification regardless of any contextual bias. Therefore, we should try at least two contexts in negation tests: one encouraging people to assign 0 to the prejacent and the other to the exhaustification. If the prejacent is presuppositional, people would have to assign 1 to it even under the former context.

A similar concern comes out in the question test in (38). Suppose again that both the prejacent and exhaustification of dake are at issue. Suppose also that people tend to already know that the prejacent is true when they ask (38a). In this case, there is still be something in question (namely, the truth value of the exhaustification), and thus, the question (38a) is not completely redundant.

Given this concern about the standard presupposition tests in (37) and (38), I propose an enhanced versions of negation tests, in which target inferences (prejacent and exhaustification here) are examined one by one with different contextual 
Scalar implicatures in non-monotonic environments

biases. Let us first check whether the restrictive particles presuppose their prejacent. Consider (41)-(42)under the context in (40).

(40) Context: You already know that every boy other than John got into mischief. It just turned out that John also did it.

(41) \# Because John got in mischief as well, it is not the case that only John is a good boy.

(42) John-datte itazura-si-tan-dakara, John-also mischief-do-PST-because

'Because John also got in mischief,'

a. JOHN-dake ii-ko-na wakejanai. John-only good-child-COP it.is.not.the.case

b. \# JOHN-shika ii-ko-de-nai wakejanai. John-only good-child-COP-NEG it.is.not.the.case

'it is not the case that only John is a good child.'

The because-clauses in (41-42) (and the context in (40)) imply that John is not a good boy/child. Therefore, people are encouraged to negate the prejacent (= John is a good boy/child) in order to avoid contradiction. If a restrictive particle presupposes its prejacent, however, it must be preserved under negation, and thus, would necessarily cause a contradiction with the because-clauses (and the context). Only, which has been proposed to presuppose its prejacent (Horn 1969; von Fintel 1999), in fact exhibits a contradiction in (41). We obtain the same result with shika (42b), which I assumed is semantically equivalent to only. Dake, on the other hand, does not show any contradiction (42a). This indicates, contrary to Yoshimura's observation, that the prejacent of dake is not presupposed.

What about the exhaustification? We must employ a different context to test whether the exhaustification is presupposed or not. Consider (44)-(45) under the context in (43).

(43) Context: You already know that John volunteered. It just turned out that another boy, Bill, also did.

(44) Because Bill also volunteered, it is not the case that only John is a good boy.

(45) Bill-mo volunteer-si-tan-dakara,

Bill-also volunteer-do-PST-because

'Because Bill also volunteered,'

a. JOHN-dake ii-ko-na wakejanai.

John-only good-child-COP it.is.not.the.case 
b. JOHN-shika ii-ko-de-nai wakejanai.

John-only good-child-COP-NEG it.is.not.the.case

'it is not the case that only John is a good child.'

In (44) and (45), the content of the because-clause is changed such that it leads to a contradiction with the exhaustification (= everyone other than John is not a good boy/child). Thus, if the exhaustification is presupposed and is not flipped by the negation, the sentence would be infelicitous. The result is that none of the three particles shows infelicity, which indicates that their exhaustifications are all at issue. Therefore, the enhanced negation tests suggest dake asserts both its prejacent and exhaustification (i.e. SNM) while only and shika assert their exhaustification and presuppose their prejacent (i.e. SDE). And thus, the analysis in $\$ 3.2$ correctly predicts SIs can be embedded in dake's exhaustification.

\section{Conclusion}

This paper confirmed, with a new example, the previous observation that SIs can be embedded in the scope of SNM operators. I also clarified a problem of postsemantic analyses: they require partial weakening to derive SIs embedded in SNM environments. On the other hand, I pointed out that there are also NM environments that disallow SI-embedding in their negative component: namely, SDE and SUE environments. Following Sharvit \& Gajewski (2008) and Gajewski \& Sharvit's (2012) proposal, I showed that whether an SI applies or not is independently determined in assertions and presuppositions. SNM operators allow SIs even in its negative inference because it has no presupposition and thus it is impossible to strengthen the positive and negative inferences independently. The SNMity of dake, which is not necessarily taken for granted in the previous literature, is supported by my enhanced version of negation tests.

\section{Appendix Presupposition tests on almost}

In $§ 3.1 .3$, I assumed that almost is SUE: it asserts its positive inference and presupposes its negative inference (Ducrot 1973; Horn 1996). Let me now support this assumption with the enhanced version of negation tests. First, (47a) confirms that the positive inference is not presupposed, under the context in (46).

(46) Context: John is a student who registered for a math class. He got the full scores in the midterm and final exams. However, he did not submit any of 5 assignments, which counted as $30 \%$ of the total grade. Accordingly, he got a C. In order to get an A, one must have $90 \%$ or a higher numerical grade. Now, you just heard some people saying that John failed to get an A because 
Scalar implicatures in non-monotonic environments

the class had many other brilliant students and the instructor had to curve the grades. They claimed that John would have got an A without that strong bell curve effect. But you know that John's numerical grade was too low in the first place, so they must be wrong.

(47) Since his numerical grade was just $70 \%$,

a. it is not the case that John almost got an A in the class.

b. it is not the case that John was on the border between A and B.

The context and the since-clause above are designed so that they encourage people to negate the positive inference (= John came close to A). If the inference is at issue, it is flipped by the negation and would not contradict the context or the since-clause which imply that John was far away from getting an A. (47b), which is supposed to entail the positive inference of almost alone, in fact shows no contradiction. If the inference is presupposed, on the other hand, it cannot be flipped by the negation, so there would be a contradiction with the context and the since-clause. In (47b), I provide an assertion of the positive inference of almost without the negative inference (= John did not ace the class) and it shows no contradiction. Just like this, (47a) is judged felicitous, which indicates that the positive inference is at issue there.

On the other hand, (47b) shows that the negative inference is presupposed.

(48) Context: John is a student who is majoring in math and aced every class he took. You just heard someone saying that John got a B in a math class even though he did well as usual and was actually on the border between A and B. But you know that his GPA is still 4.0, so the information must be wrong.

(49) Since his GPA is still 4.0,

a. \# it is not the case that John almost got an A in the class.

b. it is not the case that John failed to get an A in the class.

The context in (48) and the since-clause in (49) bias people to negate the negative inference of almost (= John did not ace the class). The infelicity of (49a) indicates that they fail to negate this inference even in the context, and thus, the inference is presuppositional. Note that the sentence becomes felicitous when we pick up the negative inference alone as an assertion as in (49b). The enhanced negation tests above support the assumption that almost is SUE.

\section{References}

Atlas, Jay David. 1997. Negative adverbials, prototypical negation and the De Morgan taxonomy. Journal of Semantics 14(4). 349-367. 
Atlas, Jay David \& Stephen C. Levinson. 1981. It-clefts, informativeness, and logical form. In Peter Cole (ed.), Radical Pragmatics, 1-61. New York: Academic Press.

Chierchia, Gennaro. 2004. Scalar implicatures, polarity phenomena, and the syntax/pragmatics interface. In Adriana Belletti (ed.), Structures and Beyond, 39103. New York: Oxford University Press.

Chierchia, Gennaro. 2006. Broaden your views: Implicatures of domain widening and the "logicality" of language. Linguistic Inquiry 37(4). 535-590.

Chierchia, Gennaro, Danny Fox \& Benjamin Spector. 2011. Scalar implicature as a grammatical phenomenon. In Claudia Maienborn, Klaus von Heusinger \& Paul Portner (eds.), Semantics: An International Handbook of Natural Language Meaning, 2297-2331. Berlin; New York: De Gruyter Mouton.

Cohen, Laurence Jonathan. 1971. Some remarks on Grice's views about the logical particles of natural language. In Yehoshua Bar-Hillel (ed.), Pragmatics of natural languages, 50-68. Dordrecht, Holland: D. Reidel Publishing Company.

Ducrot, Oswald. 1973. La Preuve et le dire. Paris: Maison Mame.

Fauconnier, Gilles. 1975. Pragmatic scales and logical structure. Linguistic Inquiry 6(3). 353-375.

von Fintel, Kai. 1999. NPI licensing, Strawson entailment, and context dependency. Journal of Semantics 16(2). 97-148.

Fox, Danny. 2007. Free choice disjunction and the theory of scalar implicatures. In Uli Sauerland \& Penka Stateva (eds.), Presupposition and implicature in compositional semantics, 71-120. New York: Palgrave Macmillan.

Fox, Danny \& Benjamin Spector. To appear. Economy and embedded exhaustification. Natural Language Semantics .

Gajewski, Jon \& Yael Sharvit. 2012. In defense of the grammatical approach to local implicatures. Natural Language Semantics 20(1). 31-57.

Gazdar, Gerald. 1979. Pragmatics : implicature, presupposition and logical form. New York: Academic Press.

Grice, Paul. 1975. Logic and conversation. In Peter Cole \& Jerry L. Morgan (eds.), Syntax and Semantcis 3: Speech Acts, 41-58. New York: Academic Press.

Horn, Laurence R. 1969. A presuppositional analysis of only and even. In Chicago Linguistic Society (CLS) 5, 97-108. Chicago: University of Chicago.

Horn, Laurence R. 1972. On the semantic properties of logical operators in English: UCLA PhD dissertation.

Horn, Laurence R. 1985. Metalinguistic negation and pragmatic ambiguity. Language 61(1). 121-174.

Horn, Laurence R. 1989. A natural history of negation. Chicago: University of Chicago Press.

Horn, Laurence R. 1996. Exclusive company: Only and dynamics of vertical infer- 
Scalar implicatures in non-monotonic environments

ence. Journal of Semantics 13(1). 1-40.

Horn, Laurence R. 2002. Assertric inertia and NPI licensing. In Mary Andronis, Erin Debenport, Anne Pycha \& Keiko Yoshimura (eds.), Chicago Linguistic Society (CLS) 38, 55-82. Chicago: Chicago Linguistics Society.

Kuno, Susumu. 1999. The syntax and semantics of the dake and sika constructions. Harvard Working Paper in Linguistics 7. 144-172.

Levinson, Stephen. 2000. Presumptive meanings. Cambridge, MA: MIT Press.

Mogi, Toshinobu. 2001. Toritateshi 'sika'-ni okeru 'yosou'-ni tsuite [On "expectation" of the focus particle SIKA]. In Tsukuba Daigaku Touzai Gengo Bunkano Ruikeiron Tokubetsu Project Kenkyu Seika Houkokusho, Heisei 12-nendo, Bessatsu'Nihongo-no Toritate' [Progress report of the special project on typology of Eastern/Western language culture at Tsukuba University, 2001, 'Focus in Japanese'], 231-250. Tsukuba: Tsukuba University.

Numata, Yoshiko. 2000. Toritate [Focus]. In Yoshio Nitta \& Takashi Masuoka (eds.), Toki, hitei, toritate [Time, negation, and Focus], 151-216. Tokyo: Iwanami Shoten.

Russell, Benjamin. 2006. Against grammatical computation of scalar implicatures. Journal of Semantics 23(4). 361-382.

Sharvit, Yael \& Jon Gajewski. 2008. On the calculation of local implicatures. In Charles B. Chang \& Hannah J. Haynie (eds.), The West Coast Confrence on Formal Linguistics (WCCFL) 26, 411-419. Somerville, MA: Cascadilla Proceedings Project.

Spector, Benjamin. 2013. Bare numerals and scalar implicatures. Language and Linguistics Compass 7. 273-294.

Yoshimura, Keiko. 2007. Focus and polarity: even and only in Japanese: The University of Chicago $\mathrm{PhD}$ dissertation.

Takashi Morita

MIT Linguistics and Philosophy

77 Massachusetts Avenue

Bldg. 32-D808

Cambridge, MA 02139 USA

tmorita@mit.edu 